\title{
Effects of environmental context changes on memory
}

\author{
RICHARD DOLINSKY \\ University of Toledo, Toledo, Ohio \\ and \\ KAREN ZABRUCKY \\ Clemson University, Clemson, South Carolina
}

\begin{abstract}
The present study examined the effects of environmental context changes on memory. Word lists were presented auditorily to subjects who were in a normal-vision or a restricted-vision context and were recalled immediately after in the same or a different state. A marginally significant memory decrement was found when the environmental context occurring during recall differed from that occurring during learning. Importantly, this memory decrement was not manifested throughout all serial positions in the word lists. Although different-context conditions resulted in significantly poorer memory for "middle" and "recency" items, they actually benefited memory for "primacy" items. The results are discussed in terms of the retrieval strategies used by subjects in the same-and different-context conditions.
\end{abstract}

Many studies over the last decade have demonstrated that the particular contexts occurring during both the initial encoding of and the recall of information can have a substantial effect on memory for the information. Investigators who have addressed the issue of the contextdependent nature of memory have used a large variety of contexts in their studies, although most such contexts can be classified according to one of two types: experiential contexts, that is, the "inner states of the experiencing person which affect the way he views or remembers the same stimulus material" (Reiff \& Scheerer, cited in Eich, Weingartner, Stillman, \& Gillin, 1975, p. 416) and environmental contexts, or "stimulation from the external environment, such as the furniture in the room, the experimenter, and the apparatus" (McGeoch, cited in Eich et al., 1975, p. 416).

The majority of studies have investigated the effects of experiential states occurring during encoding or recall on memory. The data from these studies can be summarized by the repeated finding that subjects who learn and recall information in the same state have better memory for the information than do those learning and recalling the information in disparate states. Typically, the states investigated during learning and recall have been pharmacological states (e.g., Eich et al., 1975; Goodwin, Powell, Bremer, Hoine, \& Stern, 1969; Weingartner, Adefris, Eich, \& Murphy, 1976; for review, see Eich, 1980), although context-dependent memory has been demonstrated in affective or emotional mood states as well

Requests for reprints may be sent to Karen Zabrucky, Department of Psychology, Clemson University, Clemson, South Carolina 29631. (e.g., Bower, Monteiro, \& Gilligan, 1978; Leight \& Ellis, 1981; Macht, Spear, \& Levis, 1977).

The present study was concerned with the role of context in memory but assessed the role of environmental context cues occurring during encoding and recall rather than that of cues that may be provided by the inner pharmacological or emotional mood state of the individual. Previous investigations of environmental context changes on memory have shown that retroactive inhibition is diminished when interpolated learning occurs in an environmental context that is different from that in which original learning occurred (Strand, 1970). Memory has also been found to be better when learning and recall occur in the same environmental contexts than when they occur in different contexts. For example, Smith (1979) and Smith, Glenberg, and Bjork (1978) demonstrated that subjects' memory for word lists was better when learning and recall occurred in the same rooms than when they occurred in different rooms, and Godden and Baddeley (1975), in an investigation of context-dependent memory using "natural" environments, found that divers who learned word lists either underwater or on dry land recalled better when the tests were conducted in the same contexts. Presumably, memory is dependent on the environment because of contextual associations, or "connections in memory between what is learned and the environmental context in which learning takes place" (Smith, 1979, p. 461; see Smith, 1979, and Smith et al., 1978, for a discussion of hypotheses concerning how such associations might be formed).

However, although many investigations of environmental context changes have found memory decrements 
for different-context conditions, some have not. For example, two of Smith et al.'s (1978) experiments (Experiments 4 and 5 failed to find a memory decrement, as did investigations by Devane and Parkman (1978) and Nixon and Kanak (1981). The former two failures to obtain an effect of environmental context change on memory can probably be attributed to the type of recall test given; that is, both studies used cued rather than noncued tests (recognition and paired-associate tests, respectively). The context or state occurring during recall plays a lesser role in subjects' memory processes when their recall is tested by a cued test, that is, a test that provides the subject with very powerful retrieval cues, than when it is tested with a noncued test, that is, a test that provides subjects with only minimal retrieval cues (see Eich, 1980 , for a discussion of this issue).

Still, Nixon and Kanak (1981) failed to find a memory decrement with an environmental context change despite their use of a noncued (free-recall) test. They suggested that their negative findings might be due to the fact that they used shorter word lists and shorter retention intervals than had been used in previous studies. Nixon and Kanak (1981) argued that lengthier word lists and longer retention intervals "should have increased task difficulty as well as duration of exposure to the original context and thus, also increased a subject's intentional or unintentional use of contextual cues" (p. 239).

Because of the paucity of research in this area and the lack of systematic investigation of many experimental variables that might influence environmental context effects, Nixon and Kanak's (1981) argument raises an interesting question, namely, whether list length and/or retention interval might interact with context dependency. Their study also raised another interesting question, that is, whether the memory decrement typically found with longer retention intervals and lengthier word lists occurs across all serial positions within the lists. Studies of context dependency typically have not examined the memory decrement associated with an environmental context change as a function of the serial positions of items. In fact, many investigators have either designed their studies to eliminate the "recency effect" that is typical of free-recall curves (e.g., Godden \& Baddeley, 1975; Strand, 1970) or excluded both the number of "primacy" and "recency" items correct frem their analyses to control for serial position effects (e.g., Smith et al., 1978). Nixon and Kanak, however, did examine the effects of environmental context changes for primacy and recency items (the first 5 and last 5 words, respectively, in 35-word lists). Although the interaction between the serial position of words and the environmental context during recall was only marginally significant, Nixon and Kanak did find an unexpected trend. For recency items, they found a memory decrement for different-context conditions, but for primacy items, they actually found a slight memory improvement for different-context condi- tions. Nixon and Kanak concluded that memory for the recency, or short-term-memory, items should be hindered by an environmental context change, since these items are "continuing to be in temporal contiguity with environmental cues" (p. 238), whereas memory for the primacy, or long-term-memory, items should not. If their analysis was correct, then the "middle" items in lists, like the primacy items, should not show a memory decrement for the different-context conditions, since these items are also, presumably, retrieved from longterm memory. In fact, at least for short word lists, only memory for the last few items in lists should show the decrement.

The purpose of the present study was to conduct a more systematic investigation of the effects of environmental context changes on memory as a function of the serial position of items within short word lists. We were interested in two separate issues: first, whether we would find the memory decrement when learning and recall (immediate-recall test) of word lists occurred in different environmental contexts, and second, whether the decrement, if found, would be manifested equally across all serial positions within the lists. Nixon and Kanak's (1981) analysis suggested that the decrement should be found only for recency items when short lists and retention intervals are used, whereas primacy items may actually show memory enhancement.

Previous investigators (Godden \& Baddeley, 1975; Nixon \& Kanak, 1981; Smith, 1979; Smith et al., 1978; Strand, 1970) have noted the importance of controlling, when manipulating the number of environmental contexts occurring between encoding and recall, the "psychological disruptance" that subjects experience. For example, subjects in different-context conditions, who are moved from one room to another between the learning and recall phases of the experiment, not only are exposed to novel contexts but also experience disruption, whereas subjects in same-context conditions experience neither novel contexts nor disruption, unless the latter variable has been controlled. Strand (1970) showed that disruption alone can produce diminished retroactive inhibition as much as can change of context alone.

In the present study, psychological disruption was controlled across same-different environmental contexts. The subjects remained in a single laboratory room throughout the experimental session. Rather than bringing the subjects to a novel context, for example, a new room, change of context was manipulated by allowing the subjects to have either normal vision of their environment, namely, of the objects in the laboratory room, or by restricting their vision with special goggles that were equipped with an opaque eye shade that could be flipped up (to allow normal vision) or flipped down (to produce restricted vision) almost instantaneously. Thus, the two environmental contexts that could occur during either learning or recall were a normal-vision context and a restricted-vision context. Word lists were 
presented auditorily to subjects who were in the normalvision or the restricted-vision state, and were recalled immediately after in the same or different state.

\section{METHOD}

\section{Subjects}

The subjects were 16 introductory psychology students, who were given course credit for their participation. The students were tested individually.

\section{Design}

The design was the standard one used in most studies of context- or state-dependent learning in which two contexts or states occurring at the time of acquisition are crossed with the same contexts or states at the time of recall. In the present experiment, the environmental context occurring during acquisition or recall was manipulated by having subjects either learn lists of words in a visually normal $(\mathrm{N})$ or visually restricted $(\mathrm{R})$ environment and recall the lists in either the same or a different environment. A factorial crossing of the two acquisition and two recall contexts resulted in the following four experimental conditions, with each subject serving in each condition: learn (vision normal), recall (vision normal) (NN); learn (vision restricted, recall (vision normal) (RN); learn (vision normal), recall (vision restricted) (NR); and learn (vision restricted), recall (vision restricted) (RR).

\section{Procedure}

Each subject learned two 18-word lists (all common nouns) in each condition, for a total of eight lists, each presented for only one trial. Whereas the two lists for a specific condition followed each other during presentation, individual lists were counterbalanced over conditions, and the order of the four conditions was counterbalanced over subjects.

Each list was presented auditorily to the subjects by tape recorder. Words within lists were presented at a 2 -sec rate. Immediately following the presentation of each list, the subjects were given a free-recall test of the list. The subjects recalled words aloud, and were given $40 \mathrm{sec}$ for recall during each of the eight test periods.

During both the list-acquisition and list-recall phases of the experiment, the subjects remained in a single laboratory room that contained tables, chairs, tape recorders, a file cabinet, and other miscellaneous equipment. During the entire experimental session, the subjects wore a pair of Morsafe welder's goggles, which were equipped with a flip-up opaque eye shade. When the shade was flipped up, the subjects were normally sighted, with the small exception of the outside frame of the goggles, and were thus exposed to a standard laboratory environment. When the shade was down, the subjects' vision was restricted; that is, the subjects were "blindfolded." The subjects were instructed by the experimenter when to flip the shade up or down; switching between environmental contexts could be accomplished almost instantaneously.

\section{RESULTS}

An analysis of variance revealed that neither the environmental context during learning nor that during recall had a significant main effect on free-recall performance $[F(1,15)<1$ and $F(1,15)=3.03, p>.05$, respectively]. Thus, the normal-vision and restricted-vision contexts seemed equally effective. The main results of interest are the effects of same or different learning and. recall contexts on memory. In the same-context conditions, scores are pooled over Conditions NN and RR; for the different-context conditions, scores are pooled over Conditions RN and NR. Although memory was better in the same-context conditions than in the different-context conditions, the superiority was only marginally significant $[F(1,15)=3.84, p<.10]$. An explanation for the failure to obtain a significant superior memory effect for the same-context conditions was suggested when we examined the serial position curves for the same- and different-context groups. There were important differences between the curves for the two groups. For the first three serial positions, the different-context groups showed a strong primacy effect, with recall significantly better than that in the same-context groups $[F(1,15)=$ $6.25, \mathrm{p}<.025]$. However, from Serial Position 4 the situation was reversed; that is, the same-state group showed better recall $[\mathrm{F}(1,15)=8.56, \mathrm{p}<.025]$ and a stronger recency effect. Further analysis indicated that, although these findings are consistent over both lists in each condition, the list presented first in each condition showed an even stronger recency effect for the samestate groups.

\section{DISCUSSION}

Two results of interest emerged in the present study. First, whether learning and recall occurred in the same or in different environmental contexts affected memory: Memory for word lists was better when subjects were tested for recall in the same contexts, although this superiority was only marginally significant. Second, the memory decrement found for differentcontext conditions was not manifested throughout all serial positions in the word lists. Although different-context conditions resulted in significantly poorer memory for words in Serial Positions $4-18$, they actually benefited memory for the first three words in the lists, producing significantly higher levels of recall than did same contexts. Thus, although the results of the present study replicated the "crossover" trend found by Nixon and Kanak (1981) for primacy and recency items-namely, poorer memory in different-context conditions for recency items but better memory in different-context conditions for primacy items-the results did not support their contention that the only list items that would be adversely affected by environmental context changes are those that are in "temporal contiguity" with environmental cues, that is, recency items. In the present study, middle list items were also adversely affected by environmental context changes. Thus, the environmental context changes did not serve merely to disrupt items in short-term memory, since many items occurring earlier in the lists were also poorly recalled. However, only the primacy items benefited from a change in environmental context during recall.

The finding of superior memory for primacy items in the different-context conditions suggests that the subjects in the same- and different-context conditions used different retrieval strategies during recall. It is clear that the differences in the serial position curves between the same- and different-state conditions were due to retrieval rather than to storage effects, since (at least for the first list in each condition) the subjects did not know whether recall would be in the same or a different state until the recall stage occurred. Therefore, recall state could not affect learning or storage of information. An examination of inputoutput relationships in the recall protocols indicated that, in the same-state conditions, the subjects tended to output first the last items in the list, whereas, in the different-state conditions, the subjects tended to output early and late items in the list with about equal frequency during the beginning of recall. When faced with different learning and recall states, it appears that 
subjects expect to be disrupted and perhaps feel that the earlier presented items will be the most susceptible to disruption. Consequently, they may adopt a strategy whereby earlier presented items are recalled first, before they are forgotten.

Both the present study and the one conducted by Nixon and Kanak (1981) failed to find significant overall memory decrements as a function of environmental context changes during recall. Both studies used shorter lists and retention intervals than those used by previous investigators, and both studies found that memory decrements for different-context conditions were not manifested equally throughout all serial positions in short lists. In fact, different-context conditions resulted in memory enhancement for some serial positions. The fact that previous investigations using lengthier retention intervals and word lists have found a larger overall memory decrement for environmental context changes raises an important question concerning the locus of the decrement. Is the overall decrement larger because it occurs equally throughout all serial positions in lengthier lists or when longer retention intervals are used, because memory for the recency items is especially hindered, or even, perhaps, because the "crossover" effect associated with primacy-item recall for short lists and retention intervals does not occur? Further investigations of environmental context changes are needed to examine the effects of both length of lists and retention intervals on memory across serial positions.

The results of the present study suggest that it is important to examine the effects of environmental context changes on memory as a function of the serial position of list items. The present findings indicate that excluding the primacy and recency items from statistical analyses to control for serial position effects may result in larger memory differences between same-state and different-state conditions. However, the present results also indicate that exclusion of these items will result in the loss of valuable information concerning both the nature of the retrieval strategies used by subjects experiencing environmental context changes and information concerning the locus of the memory decrement associated with such changes.

\section{REFERENCES}

Bower, G. H., Monteiro, K. P., \& Gilligan, S. G. Emotional mood as a context for learning and recall. Journal of Verbal Learning and Verbal Behavior, 1978, 17, 573-585.

Devane, J. R., \& Parkman, R. A. Effects of imagery instructions when the context is changed. Perceptual and Motor Skills, 1978, 46, 716-718.

Еiсн, J. E. The cue-dependent nature of state-dependent retrieval. Memory \& Cognition, 1980, 8, 157-173.

Eich, J. E., Weingartner, H., Stillman, R. C., \& Gillin, J. C. State-dependent accessibility of retrieval cues in the retention of a categorized list. Journal of Verbal Learning and Verbal Behavior, 1975, 14, 408-417.

Godden, D. R., \& Baddeley, A. D. Context-dependent memory in two natural environments: On land and underwater. British Journal of Psychology, 1975, 66, 325-331.

Goodwin, D. W., Powell, B., Bremer, D., Hoine, H., \& STERN, J. Alcohol and recall: State-dependent effects in man. Science, 1969, 163, 1358-1360.

Leight, K. A., \& Ellis, H. C. Emotional mood states, strategies, and state-dependency in memory. Journal of Verbal Learning and Verbal Behavior, 1981, 20, 251-266.

Macht, M. L., Spear, N. E., \& Levis, D. J. State-dependent retention in humans induced by alterations in affective state. Bulletin of the Psychonomic Society, 1977, 10, 415-418.

Nixon, S. J., \& KanaK, N. J. The interactive effects of instructional set and environmental context changes on the serial position effect. Bulletin of the Psychonomic Society, 1981, 18, 237-240.

Sмiтh, S. M. Remembering in and out of context. Journal of Experimental Psychology: Human Learning and Memory, 1979, $5,460-471$.

Smith, S. M., Glenberg, A., \& BJork, R. A. Environmental context and human memory. Memory \& Cognition, 1978, 6, 342-353.

Strand, B. Z. Change of context and retroactive inhibition. Journal of Verbal Learning and Verbal Behavior, 1970, 9, 202-206.

Weingartner, H., Adefris, W., Eich, J. E., \& Murphy, D. L. Encoding-imagery specificity in alcohol state-dependent learning. Journal of Experimental Psychology: Human Learning and Memory, 1976, 2, 83-87.

(Manuscript received for publication August 15, 1983.) 